\title{
COMBINED MEASUREMENTS OF WATER AND SEDIMENT DISCHARGES AND SURFACE VELOCITY OF MIDTDALSBREEN, NORWAY
}

\section{(Abstract)}

\author{
by \\ Ian Willis \\ (Department of Geography, University of Cambridge, Downing Place, Cambridge CB2 3EN, \\ England, U.K.)
}

\begin{abstract}
Because high suspended sediment concentration (SSC) in melt waters may cause damage to hydro-electric powergenerating machinery, the ability to predict the suspended sediment loads of pro-glacial streams is important for economic reasons. The study to which this abstract refers examines how the sliding velocity of a glacier might help to account for some of the variance of SSC in a pro-glacial stream, which is otherwise accounted for neither by diurnal and seasonal fluctuations in melt-water discharge nor by variations in the supply and exhaustion of sediment.

Anomalies in SSC of pro-glacial streams occur, of ten without any noticeable change in discharge. Pulses of turbid water during the mini-surges of Variegated Glacier (Humphrey and others, 1986) were attributed to the tapping of new local sediment sources beneath the glacier during the shifting of drainage routes. Such anomalies are significant in the transport of suspended sediment in pro-glacial streams, and cannot be estimated by using sediment-rating curves. Our study reports patterns of water discharge, SSC, and glacier velocity of Midtdalsbreen, a northern outlet glacier of Hardangerjøkul in south Norway. The glacier is $1 \mathrm{~km}$ wide and about, $5 \mathrm{~km}$ long, in the altitude range $1400-1830 \mathrm{~m}$, and covers $77 \%$ of a catchment area of about $9 \mathrm{~km}^{2}$.

Between 22 June and 21 August 1987, water discharge and rainfall were recorded hourly at a site $600 \mathrm{~m}$ from the glacier snout. Water samples, collected every $2 \mathrm{~h}$, were filtered in the field and returned to the laboratory where SSC was determined. Glacier-surface velocities were calculated by repeatedly surveying the position of four fixed markers on the centre line of the glacier at spacings of about $350 \mathrm{~m}$. Between 7 July and 29 August, when weather permitted, surveys were made five times daily and a 2 hourly velocity-time series was synthesized using cubic spline interpolation for each of the four markers.

In order to explain as much as possible of the variation in SSC, a statistical model was produced and residuals from the model were analysed to see whether any of the large positive residuals occurred at times of short-term increases in glacier velocity. After transforming the variables by taking $\log _{10}$, several models were produced. The suitability of each model was assessed on the basis of the significance of the model parameters, the magnitude of the residual sum of squares (RSS), and absence of pattern in the autocorrelation function (acf) and the partial acf of the residuals.
\end{abstract}

\section{Linear regression}

An ordinary rating curve was fitted to the data. Although over $52 \%$ of the variance in SSC was explained, serial autocorrelation in the residuals remained high.

\section{Multiple regression}

Attempts to model variations in SSC on the basis of variations in stream discharge alone suffer from the exclusion of other explanatory variables. A number of additional control variables were therefore identified: (i) To account for hysteresis, the rate of change of discharge was obtained by subtracting the preceding discharge from each recorded flow value (cf. Richards, 1984). This variable is positive during rising stages and negative during falling stages.

(ii) Five variables, the amounts of rainfall which had fallen in the previous $1,2,3,4$, and $5 \mathrm{~h}$, respectively, were used to account for sediment being flushed from the non-glacial area.

(iii) A seasonal, exhaustion-effect variable, time since the beginning of summer, was introduced.

(iv) $\mathrm{A}$ variable, days since discharge was equalled or exceeded, was created to account for the problem of storage sediment-queueing in the pro-glacial zone (Richards, 1984).

These variables were entered stepwise into a multiple regression model to explain SSC. Only three were significant at the $p=0.05$ level: discharge, rate of change of discharge, and days since discharge were equalled or exceeded. Despite the inclusion of the additional variables representing the effects of hysteresis and short-term sediment supply, the model explained only $2 \%$ more of the variance in SSC than was explained by using the ordinary rating curve, and autocorrelation residuals remained high.

\section{Univariate time-series model}

It appears that true autocorrelation exists in the residuals from the ordinary rating curve such that current values of SSC are influenced not only by discharge but also by previous levels of SSC, due to the presence of an autoregressive (AR) and/or moving-average (MA) system within the residuals. Although several AR/MA models were fitted to the SSC series, a first-differenced first-order MA with a second-order seasonal AR model was selected as the simplest, removing all the pattern from the sediment data and leaving the residuals in the form of white noise. These results may be compared with those of Gurnell and Fenn (1984). This white-noise residual series, which consists of pure, random shocks, was compared with the glaciervelocity series to determine whether apparently random increases in SSC could be linked to short-term glacier movements. Peaks in the time-series of residuals and of glacier velocity show a high degree of correspondence. Twelve of the top 25 positive residuals in the sediment series occurred simultaneously with peaks associated with short-term glacier-velocity increases for at least one of the markers.

Short-term variations in measured surface velocity at Midtdalsbreen are believed to relate to changes in sliding velocity. Many of the anomalies from the univariate SSC model occur during glacier-motion events, and are therefore believed to result from subglacial instability. Dye-tracer experiments undertaken around the centre line of Midtdalsbreen suggest that water flows in a distributed system of passageways over large areas of the bed. Such a system could provide storage spaces for unworked pockets of sediment away from flowing water. However, because of 
the near-simultaneous occurrences of glacier movements and sediment pulses in the pro-glacial stream, many of these sediment pockets must become integrated with flows in major conduits during glacier-movement events. The existence of at least two major conduits running beneath the lower glacier was indicated by other dye-tracer experiments initiated towards the glacier margins.

The hypothesis that random injections of sediment pulses may result from migration of basal streams during the re-organization of subglacial drainage channels (Collins, 1979), and that sudden movements of the glacier may release sediment to isolated subglacial drainage lines (Gurnell, 1982), is supported by this study.

\section{REFERENCES}

Collins, D.N. 1979. Sediment concentration in melt waters as an indicator of erosion processes beneath an Alpine glacier. J. Glaciol., 23(89), 247-257.

Gurnell, A.M. 1982. The dynamics of suspended sediment concentration in an Alpine pro-glacial stream. International Association of Hydrological Sciences Publication 138 (General Assembly of Exeter 1982 - Hydrological Aspects of Alpine and HighMountain Areas), 319-330.

Gurnell, A.M. and C.R. Fenn. 1984. Box-Jenkins transfer function models applied to suspended sediment concentration - discharge relationships in a proglacial stream. Arct. Alp. Res., 16(1), 93-106.

Humphrey, N., C.F. Raymond, and W. Harrison. 1986. Discharges of turbid water during mini-surges of Variegated Glacier, Alaska, U.S.A. J. Glaciol., 32(111), 195-207.

Richards, K.S. 1984. Some observations on suspended sediment dynamics in Storbregravn, Jotunheim. Earth Surface Processes and Landforms, 9, 101-112. 